\title{
The Impact of Natural Disaster on Pediatric Surgical Delivery: A Review of Haiti Six Months Before and After the 2010 Earthquake
}

\section{Citation}

Hughes, Christopher D., Katherine A. Nash, Blake C. Alkire, Craig D. McClain, Lars E. Hagander, C. Jason Smithers, Maxi Raymonville, et al. 2012. "The Impact of Natural Disaster on Pediatric Surgical Delivery: A Review of Haiti Six Months Before and After the 2010 Earthquake." Journal of Health Care for the Poor and Underserved 23 (2): 523-533. doi:10.1353/hpu.2012.0067.

\section{Published Version}

doi:doi.org/10.1353/hpu.2012.0067

\section{Permanent link}

http://nrs.harvard.edu/urn-3:HUL.InstRepos:32202877

\section{Terms of Use}

This article was downloaded from Harvard University's DASH repository, and is made available under the terms and conditions applicable to Other Posted Material, as set forth at http:// nrs.harvard.edu/urn-3:HUL.InstRepos:dash.current.terms-of-use\#LAA

\section{Share Your Story}

The Harvard community has made this article openly available.

Please share how this access benefits you. Submit a story.

Accessibility 


\title{
The Impact of Natural Disaster on Pediatric Surgical Delivery: A Review of Haiti Six Months Before and After the 2010 Earthquake
}

\author{
Christopher D. Hughes, MD, MPH \\ Katherine A. Nash \\ Blake C. Alkire, MD, MPH \\ Craig D. McClain, MD, MPH \\ Lars E. Hagander, MD \\ C. Jason Smithers, MD \\ Maxi Raymonville, MD \\ Stephen R. Sullivan, MD, MPH \\ Robert Riviello, MD, MPH \\ Selwyn O. Rogers, MD, MPH \\ John G. Meara, MD, DMD, MBA
}

\begin{abstract}
Little is known about pediatric surgical disease in resource-poor countries. This study documents the surgical care of children in central Haiti and demonstrates the influence of the 2010 earthquake on pediatric surgical delivery. Methods. We conducted a retrospective review of operations performed at Partners in Health/Zanmi Lasante hospitals in central Haiti. Results. Of 2,057 operations performed prior to the earthquake, 423 were pediatric (20.6\%). Congenital anomalies were the most common operative indication (159/423 operations; $33.5 \%)$. Pediatric surgical volume increased significantly after the earthquake, with
\end{abstract}

CHRISTOPHER HUGHES is a Paul Farmer Global Surgery Research Fellow at Children's Hospital Boston and an Affiliate with the Program in Global Surgery and Social Change at Harvard Medical School. KATHERINE NASH is a research associate in the Department of Plastic and Oral Surgery, Children's Hospital Boston. BLAKE ALKIRE is a research associate in the Department of Plastic and Oral Surgery, Children's Hospital Boston. CRAIG MCCLAIN is an Associate in Perioperative Anesthesia, Children's Hospital Boston, and an Associate Professor in the Department of Anesthesia, Harvard Medical School. LARS HAGANDER is a Paul Farmer Global Surgery Research Fellow at Children's Hospital Boston and an Affiliate with the Program in Global Surgery and Social Change at Harvard Medical School. JASON SMITHERS is an Assistant in Surgery, Children's Hospital Boston and an Instructor at Harvard Medical School. MAXI RAYMONVILLE is an OBGYN physician with Partners in Health and Zanmi Lasante in Haiti. STEPHEN SULLIVAN is an Assistant Professor of Surgery, Brown University Warren Alpert Medical School and Hasbro Children's Hospital. ROBERT RIVIELLO is an Instructor of Surgery, Harvard Medical School. SELWYN ROGERS is the Chief of Trauma, Critical Care, and Burns at Brigham and Women's Hospital. JOHN MEARA is the Surgeon-in-Chief of the Department of Plastic and Oral Surgery, Children's Hospital Boston, and the Director of the Program in Global Surgery and Social Change, Harvard Medical School. Please address correspondence to Christopher Hughes, MD, MPH, 300 Longwood Ave., Enders 10, Boston, MA 02115; (617) 755-7548; chughes414@gmail.com. 
670 operations performed (23.0\% post-earthquake $v .20 .6 \%$ pre-earthquake, $\mathrm{p}=.03$ ). Trauma and burns became the most common surgical diagnoses after the disaster, and operations for non-traumatic conditions decreased significantly $(\mathrm{p}<.01)$. Conclusion. Congenital anomalies represent a significant proportion of baseline surgical need in Haiti. A natural disaster can change the nature of pediatric surgical practice by significantly increasing demand for operative trauma care for months afterward.

Key words: Pediatrics, surgery, resource-poor settings, burden of surgical disease, natural disaster.

$\mathrm{P}$ ediatric populations are often disproportionately large in developing countries. In Haiti, for example, roughly $37 \%$ of the population is under 15 years of age, compared with roughly $20 \%$ in the United States and $18 \%$ in the United Kingdom. ${ }^{1}$ Little is known about the scale or scope of surgically treatable conditions affecting children in resource-poor areas. Without care, children with otherwise surgically-treatable diseases face a life of unnecessary morbidity and truly represent the neglected stepchildren, as it were, of public health efforts in low and middle income countries (LMICs). ${ }^{2}$ Global health efforts in LMICs should address these surgical needs of children.

Efforts in Africa are beginning to define the pediatric burden of surgical disease, ${ }^{3,4}$ but formalized networks for global pediatric surgery have yet to be developed. ${ }^{5}$ Even less is known about the pediatric surgical care delivered in Haiti. Because of the January 2010 earthquake, Haiti presents a unique opportunity not only to examine baseline pediatric surgical care, but also to evaluate the influence of a natural disaster on pediatric care in a resource-poor setting.

Surgical resources throughout Haiti were lacking even before the earthquake, which added a significant disease burden to an already stressed health care infrastructure. ${ }^{6}$ Partners in Health (PIH) and its Haitian sister organization Zanmi Lasante (ZL) operate hospitals throughout the Central Plateau and Artibonite region. For over 25 years, they have provided essential medical and surgical services for the nation's most needy. ${ }^{7}$ Our own recent report illustrated the ability of this pre-existing health care network to respond to the acute spike in demand for surgical services in the immediate aftermath of the earthquake, ${ }^{6}$ when much of the health care infrastructure was destroyed. Hospitals and health centers that remained intact following the disaster were stressed and stretched beyond capacity.

Subjective experience in providing surgical care to the underserved in Haiti both before and after the January 2010 earthquake suggested a substantial need for the surgical care of children in the region. With this study, our purpose is to provide objective evidence of both the baseline surgical care provided to children in central Haiti and to demonstrate the influence of the earthquake on pediatric surgical demand and provision. We hypothesized that that pediatric operations constituted a substantial component of surgical care prior to the earthquake and that post-earthquake operations were largely related to traumatic injury. 


\section{Methods}

Following approval by the institutional review boards and ethics committees of both Children's Hospital Boston and Partners in Health/Zanmi Lasante (PIH/ZL), we conducted a retrospective review of pediatric surgical volume at five PIH/ZL hospitals throughout the Central and Artibonite districts of Haiti: Cange, St. Marc, Petite Riviere, Hinche, and Belladere. We culled operative logs and included all major operations (procedures occurring in an operating room with local, regional, spinal, or general anesthesia) from July 2009 to July 2010 on all consecutive patients 18 years of age and younger. We collected data on age, gender, hometown, primary and secondary diagnoses, operation, operative time, surgeon, anesthesia type, and transfusion requirement. Primary and secondary surgical diagnoses were categorized based on previous studies (congenital anomalies, genitourinary, obstetrics and gynecology, gastrointestinal, neoplasms, infection, otolaryngology, trauma and burns, and miscellaneous). ${ }^{3}$ To determine baseline pediatric surgical volume, we analyzed pre-earthquake data from July 1, 2009 to January 11, 2010. We next compared pre- and post-earthquake (January 12, 2010 to July 1, 2010) pediatric surgical care. For trend analyses, we categorized both pre- and post-earthquake time periods into month-long blocks.

Chi-squared tests were used to determine differences between categorical variables and t-tests were used to detect differences in pre- and post-earthquake frequencies for continuous variables. The alpha threshold for significance was set at $p \leq 0.05$. All statistical tests were performed using IBM SPSS, v19.1 (Chicago, IL).

\section{Results}

Baseline pediatric surgical care. Of 2,057 operations performed in the pre-earthquake time period, 423 (20.6\%) were for pediatric patients. Most of the patients were male and the highest volume was conducted at Cange (Table 1). Children were treated for a variety of surgical diagnoses prior to the earthquake (Table 2). The most common diagnostic group was congenital anomalies (33.5\%), including hernia (21.1\%), cryptorchidism (5.1\%), and hydrocele (3.8\%). Genitourinary and obstetric and gynecologic conditions comprised a large proportion of surgical care as well (14.3\% and $13.5 \%$, respectively). Traumatic injuries constituted just 3.1\% of all operations during this time period. Specifically, surgical treatment for fracture/dislocation and burns were relatively rare $(2.1 \%$ and $0.4 \%$, respectively).

Influence of the earthquake on pediatric surgery. The demographic makeup of the pediatric surgical population was not significantly different between pre- and postearthquake groups (Table 1). Overall, PIH/ZL hospitals provided more operations for children after the earthquake than before $(n=670 v .423$ cases, respectively), and surgery for children constituted a significantly larger percentage of total operations after the earthquake $(\mathrm{p}=.03)$.

Table 3 provides univariate analyses comparing pre- and post-earthquake volume by diagnosis. Subgroup analyses were performed for the most common diagnoses related to trauma and burns and congenital anomalies. Operations for nearly all non-trauma diagnoses decreased after the earthquake. Congenital, obstetric and gynecologic, 


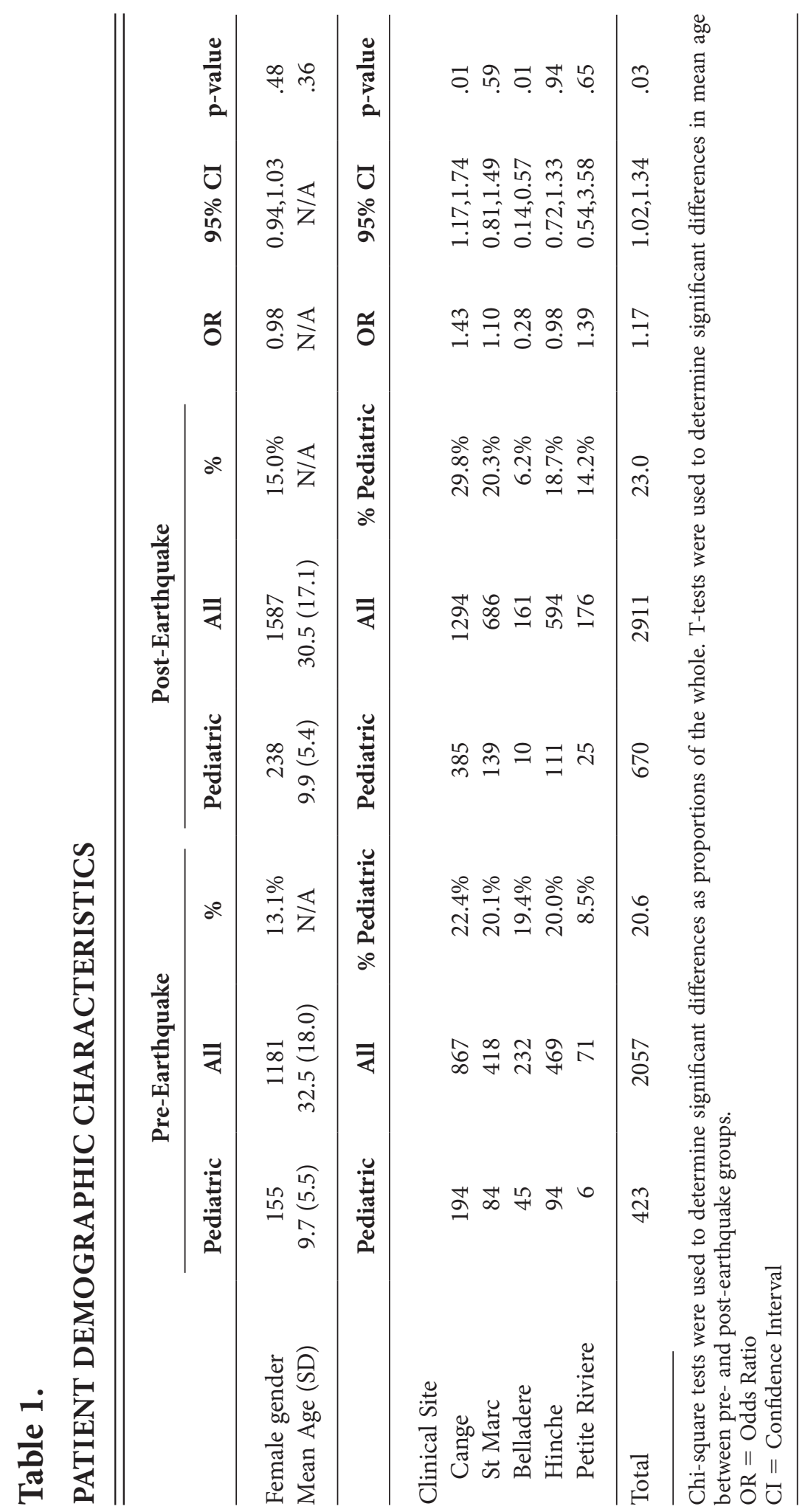




\section{Table 2.}

\section{MOST COMMON PEDIATRIC SURGICAL DIAGNOSES (PRIMARY AND SECONDARY) IN CENTRAL HAITI, PRE-EARTHQUAKE (JULY 2009-JANUARY 11TH, 2010)}

\begin{tabular}{|c|c|c|c|}
\hline Diagnosis & $\mathrm{N}=423$ & $\begin{array}{c}\% \text { of all } \\
\text { pediatric diagnoses }\end{array}$ & $\begin{array}{c}\text { Mean Age } \\
\text { in years }(\mathrm{SD})\end{array}$ \\
\hline Congenital Anomalies & 159 & 33.5 & $7.4(4.8)$ \\
\hline Hernia & 100 & 21.1 & $7.8(4.6)$ \\
\hline Cryptorchidism & 24 & 5.1 & $7.9(3.4)$ \\
\hline Hydrocele & 18 & 3.8 & $9.3(5.2)$ \\
\hline Imperforate Anus & 9 & 1.9 & $0.8(0.6)$ \\
\hline Hirschsprungs & 3 & 0.6 & $2.3(1.2)$ \\
\hline Varicocele & 1 & 0.2 & $17(-)$ \\
\hline Miscellaneous & 4 & 0.8 & $3.8(3.6)$ \\
\hline Genitourinary & 68 & 14.3 & $8.4(4.2)$ \\
\hline Phimosis/Paraphimosis & 37 & 7.8 & $8.6(4.6)$ \\
\hline Long prepuce & 21 & 4.4 & $8.4(3.9)$ \\
\hline Urinary obstruction & 1 & 0.2 & $12.0(-)$ \\
\hline Miscellaneous & 9 & 1.9 & $6.8(2.6)$ \\
\hline Obstetrics and Gynecology & 64 & 13.5 & $17.1(1.2)$ \\
\hline Other labor related & 30 & 6.3 & $17.4(0.8)$ \\
\hline CPD & 27 & 5.7 & $16.6(1.4)$ \\
\hline Eclampsia/Preeclampsia & 7 & 1.5 & $17.8(.45)$ \\
\hline Gastrointestinal & 33 & 7.0 & $7.1(4.6)$ \\
\hline Peritonitis & 9 & 1.9 & $11.2(3.3)$ \\
\hline Colostomy & 9 & 1.9 & $5.8(4.6)$ \\
\hline Appendicitis & 3 & 0.6 & $8.0(1.4)$ \\
\hline Intussusception & 1 & 0.2 & $8.0(-)$ \\
\hline Bowel obstruction & 2 & 0.4 & $7.5(0.7)$ \\
\hline Pyloric stenosis & 1 & 0.2 & $0.8(-)$ \\
\hline Miscellaneous & 8 & 1.7 & $4.2(4.0)$ \\
\hline Neoplasms & 31 & 6.5 & $12.3(4.7)$ \\
\hline Infections & 22 & 4.6 & $6.1(5.3)$ \\
\hline Abscess & 18 & 3.8 & $5.4(5.3)$ \\
\hline Osteomyelitis & 1 & 0.2 & $13.0(-)$ \\
\hline Miscellaneous & 3 & 0.6 & $8.0(5.3)$ \\
\hline Otolaryngology & 22 & 4.6 & $7.2(4.0)$ \\
\hline Tonsillitis & 19 & 4.0 & $6.4(3.2)$ \\
\hline Thyroid & 1 & 0.2 & $16.0(-)$ \\
\hline Miscellaneous & 2 & 0.4 & $14.0(-)$ \\
\hline Trauma and Burns & 15 & 3.1 & $10.9(4.8)$ \\
\hline Fracture/Dislocation & 10 & 2.1 & $12.3(4.0)$ \\
\hline Burns & 2 & 0.4 & $10.5(9.2)$ \\
\hline Amputation & 2 & 0.4 & $9.0(1.4)$ \\
\hline Miscellaneous & 3 & 0.6 & $6.7(2.9)$ \\
\hline Miscellaneous & 60 & 12.7 & $11.7(4.4)$ \\
\hline
\end{tabular}

Numbers may not sum due to missing values and/or multiple diagnoses. Ages calculated based on primary diagnoses. 
genitourinary, and otolaryngologic related operations all decreased significantly in both absolute volume and percentage of total volume ( $\mathrm{p}<.01$ for each). Conversely, procedures related to trauma and burns and miscellaneous surgical procedures, including wound debridement, increased in absolute volume and percentage of total volume $(\mathrm{p}<.01$ for each). For example, there were nine $(2.1 \%)$ operations for fracture/dislocation prior to the earthquake compared with $195(29.1 \%)$ after $(\mathrm{p}<.01)$, and all but two amputations were performed after the disaster $(\mathrm{p}<.01)$. By comparison, operations for trauma among the adult population in this region constituted $3.4 \%$ of the surgical volume preearthquake (53/1550 operations) and $16.7 \%$ post-earthquake (353/2111 operations).

The temporal trends for pediatric surgical procedures for trauma and burns are depicted in Figure 1. Following the disaster, trauma and burn-related surgical volume increased substantially above monthly pre-earthquake averages (dashed line), and it remained elevated throughout the six-month post-earthquake period.

\section{Table 3.}

INFLUENCE OF THE EARTHQUAKE ON MAJOR PEDIATRIC SURGICAL DIAGNOSES $(\mathrm{N}=1093)$

\begin{tabular}{lccccc}
\hline $\begin{array}{l}\text { Diagnosis } \\
\begin{array}{l}\text { \% of all } \\
\text { Pediatric Cases) }\end{array}\end{array}$ & $\begin{array}{c}\text { Pre- } \\
\text { Earthquake }\end{array}$ & $\begin{array}{c}\text { Post- } \\
\text { Earthquake }\end{array}$ & OR & $\mathbf{9 5 \% C I}$ & p-value \\
\hline Total Pediatric & & & & & \\
Surgical Cases & $423(100.0)$ & $670(100.0)$ & N/A & N/A & N/A \\
Trauma and Burns & $14(3.3)$ & $259(38.8)$ & 18.36 & $(10.5,32.0)$ & .01 \\
$\quad$ Fracture/Dislocation & $9(2.1)$ & $195(29.1)$ & 18.88 & $(9.58,37.3)$ & .01 \\
$\quad$ Amputation & $2(0.5)$ & $23(3.4)$ & 7.48 & $(1.76,31.9)$ & .01 \\
$\quad$ Burns & $2(0.5)$ & $9(1.3)$ & 2.87 & $(0.62,13.3)$ & .16 \\
Congenital Anomalies & $140(33.4)$ & $80(12.0)$ & 0.27 & $(0.20,0.37)$ & .01 \\
$\quad$ Hernia & $93(22.0)$ & $43(6.4)$ & 0.24 & $(0.17,0.36)$ & .01 \\
$\quad$ Cryptorchidism & $15(3.5)$ & $6(0.8)$ & 0.25 & $(0.10,0.64)$ & .01 \\
$\quad$ Hydrocele & $17(4.0)$ & $10(1.4)$ & 0.36 & $(0.16,0.80)$ & .02 \\
Obstetrics and & & & & & \\
Gynecology & $55(13.1)$ & $43(6.4)$ & 0.46 & $(0.30,0.69)$ & .01 \\
Genitourinary & $52(12.4)$ & $21(3.1)$ & 0.23 & $(0.14,0.39)$ & .01 \\
Gastrointestinal & $30(7.2)$ & $35(5.2)$ & 0.72 & $(0.43,1.19)$ & .24 \\
Neoplasms & $30(7.2)$ & $33(4.9)$ & 0.68 & $(0.41,1.12)$ & .14 \\
Infections & $22(5.3)$ & $32(4.8)$ & 0.91 & $(0.52,1.59)$ & .76 \\
Otolaryngology & $21(5.0)$ & $13(1.9)$ & 0.38 & $(0.19,0.76)$ & .01 \\
Miscellaneous & $55(13.1)$ & $151(22.6)$ & 1.9 & $(1.38,2.71)$ & .01 \\
& & & & & \\
\hline Numbers may not sum due to missing values. Frequencies based on primary diagnosis only. \\
OR = Odds Ratio \\
CI = Confidence Interval & & & & & \\
\hline
\end{tabular}




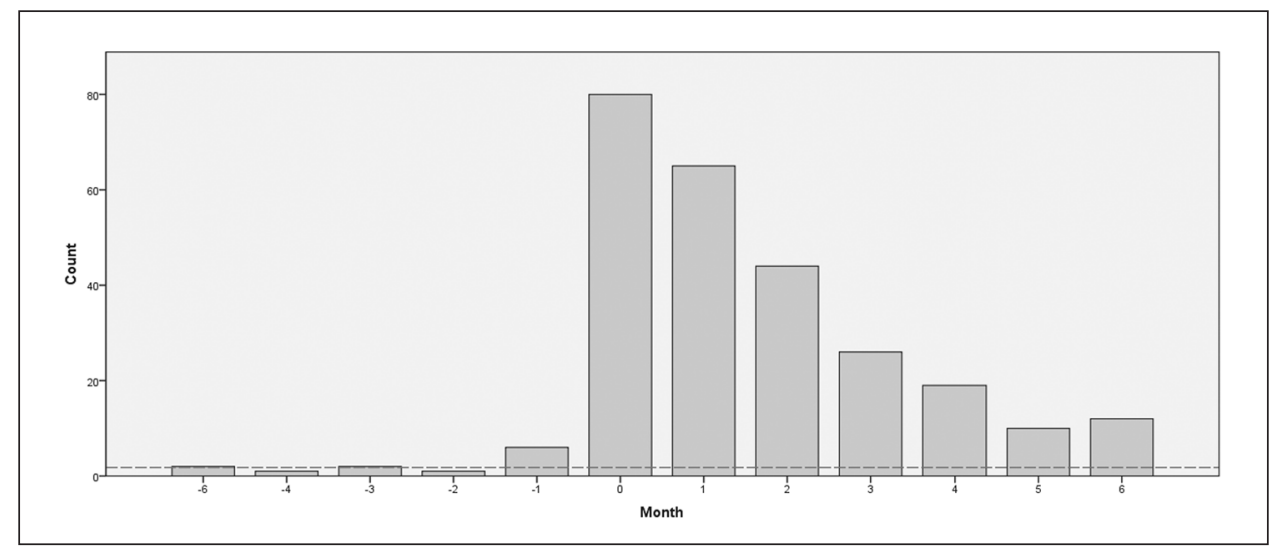

Figure 1. Trends in trauma-related pediatric surgical care by month, July 2009-July 2010.

Figures represent volume of cases. Time point 0 represents a month-long interval beginning with the earthquake on January 12,2010. The dashed referent line is defined as the pre-earthquake monthly average across all sites.

\section{Discussion}

We found a broad array of pediatric surgical disease and surgical practice in central Haiti prior to the earthquake. Following the earthquake, we noted significant changes in the scope and volume of pediatric surgical care. This study illustrates how a natural disaster is associated with the demand for, and provision of, pediatric surgical services in resource-poor settings.

The baseline epidemiologic data for pediatric surgical conditions in Haiti prior to January 2010 demonstrates the need for dedicated pediatric surgical services among this uniquely vulnerable population. Pediatric surgical volume represented a substantial portion (21-24\%) of all surgical cases at PIH/ZL hospitals, and each facility provided essential pediatric surgical care. Prior to the earthquake, for example, over one third of all pediatric operations were conducted for children with congenital anomalies. Surgery can provide effective treatment for these disease conditions that, if left untreated, would otherwise likely lead to a lifetime of morbidity, social stigmatization, and economic detriment. ${ }^{8}$

Although previous assessments in Africa have identified pediatric trauma as a leading cause of morbidity, ${ }^{3,9-11}$ we found traumatic injury to be an uncommon diagnosis leading to an operation prior to the earthquake. There are several potential explanations for our findings. Haiti lacks a network of high-speed roadways, which may decrease the potential for high-speed motor vehicle trauma. Alternatively, the lack of adequately maintained roadways may adversely affect access to timely surgical care. Additionally, due to a lack of orthopedic hardware, trained orthopedic surgeons, and intraoperative imaging capabilities at some of the PIH/ZL hospitals, many long-bone fractures are routinely treated non-operatively with traction and pinning rather than an operative reduction and fixation. Therefore, these injuries would be underrepresented in the 
operative logs. It is also likely that some pediatric trauma patients were treated at other facilities or died of their injury.

Infection was also an uncommon diagnosis in our study. In contrast, other surveys of pediatric surgical conditions in developing countries have demonstrated a significant burden of infection-related surgical disease, including osteomyelitis, pyomyositis, and abscess. ${ }^{3,12}$ Even after the earthquake, infection-related operations comprised few of the surgical cases in our cohort (5\%). Perhaps largely because the region surrounding the PIH/ZL hospitals was not significantly affected by the earthquake, living conditions may have been better than in Port-au-Prince. High infectious disease rates in tent villages and settlement camps in the capital post-earthquake contributed significantly to that population's surgical morbidity, ${ }^{13,14}$ but this was not seen among our study population. Additionally, many infection-related procedures in our population, such as wound debridements, may have been conducted outside of the operating room and thus would not have been captured by the operative log records.

The overall volume of pediatric surgery changed significantly after the earthquake. With the exception of one site, all PIH/ZL hospitals experienced an increase in surgical demand. Cange likely increased its surgical volume more than the other hospitals because of its reputation as the longest-running of the PIH/ZL hospitals and because it was the primary site for international surgical volunteers.

In addition to an increased number of children requiring surgery, the earthquake also altered the case mix. Trauma and burns became the most common indication for surgery, and congenital anomalies were a less common reason for an operation after the earthquake. This surge in trauma was likely a direct result of the disaster itself; similar results have been demonstrated among pediatric populations in field hospital reports from other disaster settings. ${ }^{9,10,11}$ Furthermore, a large group of Haitians fled the capital city in the aftermath of the earthquake, and it is possible that part of the surge in PIH/ZL trauma volume in the weeks following the disaster reflects this migration. ${ }^{15}$ Knowledge of the presence of international volunteers at PIH/ZL hospitals could also have contributed to a surge in demand for trauma surgery, even for conditions unrelated to the earthquake.

As scarce resources and personnel shifted to address acute surgical needs, the operative rates for non-traumatic causes fell among the pediatric population. Over the ensuing six months, trauma volume remained above pre-earthquake averages and non-trauma volume, including surgery for congenital anomalies, remained below average. Children with non-traumatic surgical needs were thus potentially not receiving care, and were either suffering, dying from their conditions, or experiencing a delay in surgical treatment after the earthquake. This shift represents the significant strain that natural disasters can exert in regions with limited surgical resources at baseline. Without a functional surgical delivery system in place, hospitals may not be able to meet the baseline demands of the population for an extended period of time, ${ }^{16}$ even with a significant supply of international volunteers. So, our findings reinforce the idea that a functionally sustainable surgical delivery system is essential to public health in resource-poor settings.

This analysis demonstrates that surgical care for children is a substantial and unique component of public health. Surgical diseases affecting the young are categorically 
different than those affecting adults, and additional resources should be targeted to address those needs for both individual and societal benefit. Investment in and development of surgical services for children in resource-poor settings can have significant health and economic benefits to individuals, families, and nations. ${ }^{17,18}$

Our analysis also provides insight into the way that disasters affect the surgical care of pediatric populations. Children constituted a large proportion of the injured following the Haiti earthquake: resources should be developed to accommodate the specific trauma needs of this population. In addition to the acute demand for trauma surgery, children continue to require surgical care for non-traumatic diagnoses, and international aid networks should be coordinated to address these needs. Similarly, postoperative rehabilitation services for children, especially after traumatic injury, represent an essential area of development. As this example in Haiti illustrates, natural disasters are particularly damaging to regions with limited resources. In light of the data and with the understanding that disasters will occur in the future, disaster preparedness plans must reflect the unique needs of children in resource-poor settings. ${ }^{19}$

The present study has a number of limitations. Operative data were collected via a retrospective review of each hospital's operative log. Although record-keeping was not uniformly complete across all sites, logs largely were well kept, and they provided a standard data metric that allowed our data to be comparable. The logs represent only procedures performed in the operating theatre. Additionally, our review includes only services rendered, or met need, at the point of care, and do not reflect the unmet burden of surgical disease in the region. Furthermore, we only captured six months before and six months after the earthquake. Our study time period may have been too short to account fully for potential seasonal variations either in surgical demand or in levels of international volunteers present in Haiti. Finally, PIH/ZL operate facilities in central Haiti, and we have no operative data from Port-au-Prince or other regions that were closer to the initial disaster. It is possible that the earthquake influenced surgical demand differently in these regions. ${ }^{13}$

This study provides regionally specific evidence for the significant burden of surgically treatable conditions among the pediatric population in central Haiti and how a natural disaster impacts surgical delivery. Future studies in global pediatric surgery should begin with a more comprehensive evaluation of the scope of the burden of pediatric surgical disease, including investigations of unmet need. Additionally, disaster preparedness plans specific to the needs of children should be studied and implemented in resourcepoor settings. Large numbers of both children and adults require surgery following a disaster, and limited resources often must stretch to meet the differing needs of these populations. Local health care infrastructures, whether domestically or internationally staffed, should develop plans to accommodate not only the surgical needs specific to children, but also the mental, psychological, and familial demands.

From a public health perspective, broader maternal and child health campaigns could help to address surgery's role in pediatric care. The United Nation's Millennium Development Goals 4 and 5 are targeted to improve maternal and child health, and these are intimately related to surgical care. Rather than surgery, obstetrics, and pediatric care competing, we should continue to join forces to address these common problems that unite our individual efforts. Horizontal, multidisciplinary measures 
including improvements in perinatal nutrition and education, obstetric care, and surgery can pair prevention and treatment to provide mutually reinforcing improvements for pediatric public health.

\section{Acknowledgments}

The authors would like to thank the Pyrtek Fund at Hartford Hospital and the University of Connecticut Department of Surgery for providing educational funding support for this project. Additionally, we would like to acknowledge the numerous physicians, paramedical personnel, and concerned volunteers, both Haitian and non-Haitian, who have provided care for those in need in Haiti.

\section{Notes}

1. World Health Organization. World health statistics: 2010. Geneva, Switzerland: World Health Organization, 2011. Available at: http://www.who.int/whosis/whostat /EN_WHS10_Full.pdf.

2. Farmer PE, Kim JY. Surgery and global health: a view from beyond the OR. World J Surg. 2008 Apr;32(4):533-6.

3. Bickler SW, Sanno-Duanda B. Epidemiology of paediatric surgical admissions to a government referral hospital in the Gambia. Bull World Health Organ. 2000;78(11): 1330-6.

4. Calisti A, Belay K, Mazzoni G, et al. Promoting major pediatric surgical care in a lowincome country: a 4-year experience in Eritrea. World J Surg. 2011 Apr;35(4):760-6.

5. Butler MW. Fragmented international volunteerism: need for a global pediatric surgery network. J Pediatr Surg. 2010 Feb;45(2):303-9.

6. McIntyre T, Hughes CD, Pauyo T, et al. Emergency surgical care delivery in postearthquake Haiti: partners in health and Zanmi Lasante experience. World J Surg. 2011 Apr;35(4):745-50.

7. Ivers LC, Garfein ES, Augustin J, et al. Increasing access to surgical services for the poor in rural Haiti: surgery as a public good for public health. World J Surg. 2008 Apr;32(4):537-42.

8. Semer NB, Sullivan SR, Meara JG. Plastic surgery and global health: how plastic surgery impacts the global burden of surgical disease. J Plast Reconstr Aesthet Surg. 2010 Aug;63(8):1244-8.

9. Zargar M, Sayyar Roudsari B, Shadman M, et al. Pediatric transport related injuries in Tehran: the necessity of implementation of injury prevention protocols. Injury. 2003 Nov;34(11):820-4.

10. Ademola SA, Dedeke IO, Oyelami OA. Childhood injuries in Ilesa, South-Western Nigeria: causes, patterns, and outcome. West Afr J Med. 2010 Jul-Aug;29(4):253-8.

11. Iskit $\mathrm{SH}$, Alpay $\mathrm{H}$, Tugtepe $\mathrm{H}$, et al. Analysis of 33 pediatric trauma victims in the 1999 Marmara, Turkey earthquake. J Pediatr Surg. 2001 Feb;36(2):368-72.

12. Jain V, Noponen R, Smith BM. Pediatric surgical emergencies in the setting of a natural disaster: experiences from the 2001 earthquake in Gujarat, India. J Pediatr Surg. 2003 May;38(5):663-7.

13. Farfel A, Assa A, Amir I, et al. Haiti earthquake 2010: a field hospital pediatric perspective. Eur J Pediatr. 2011 Apr;170(4):519-25.

14. Ginzburg E, O’Neill WW, Goldschmidt-Clermont PJ, et al. Rapid medical relief- 
Project Medishare and the Haitian earthquake. New Engl J Med. 2010 Mar;362(10): e31.

15. Bengtsson L, Lu X, Garfield R, et al. Internal population displacement in Haiti: preliminary analyses of movement patterns of Digicel mobile phones: 1 January to 11 March 2010. New York, NY: Columbia University/Karolinska Institutet, 2010 Aug 31. Available at: http://reliefweb.int/sites/reliefweb.int/files/resources/4DBAD332B25F98 738525772F007116F0-Full_Report.pdf.

16. Breaux JA, French M, Richardson WS. Effect of natural disaster on routine surgery. J Am Coll Surg. 2009 Sep;209(3):352-5.

17. Corlew DS. Estimation of impact of surgical disease through economic modeling of cleft lip and palate care. World J Surg. 2010 Mar;34(3):391-6.

18. Alkire B, Hughes CD, Nash K, et al. The potential economic benefit of cleft lip and palate repair in sub-Saharan Africa. World J Surg. 2011 Jun;35(6):1194-201.

19. Burke RV, Iverson E, Goodhue CJ, et al. Disaster and mass casualty events in the pediatric population. Semin Pediatr Surg. 2010 Nov;19(4):265-70. 